\title{
Dengue: la amenaza constante
}

\section{Dengue: the constant threat}

\author{
Antonio Arbo ${ }^{1,2}$
}

El dengue, enfermedad viral causada por un flavivirus-el virus del dengue que incluye cuatro serotipos, representa la arbovirosis más importante a nivel mundial, de tremendo impacto en la morbilidad y mortalidad de la población ${ }^{(1)}$. Casi la mitad de la población mundial que habita países situados entre $10^{\circ}$ de latitud norte y $10^{\circ}$ de latitud sur está en riesgo de sufrir esta infección. Se calcula que anualmente se producen alrededor de 100 millones de casos, 500.000 casos de formas severas y más de 25 000 muertes por dengue ${ }^{(2,3)}$. El dengue constituye una carga económica y produce una gran afectación en la economía en los países afectos ${ }^{(4)}$. El resurgimiento del dengue a partir de la década del 80 en nuestro continente ha coincidido con la reintroducción del vector el Aedes aegypti, cuya expansión afecta a prácticamente todo el continente excepto los extremos geográficos más fríos ${ }^{(5)}$.

Aunque la mayoría de los casos de infección sintomática son leves y no ponen en peligro la vida, en ocasiones el dengue produce cuadros que requieren hospitalización ${ }^{(6)}$. En su forma más severa cursa con choque hipovolémico por extravasación de plasma, trombocitopenia moderada o intensa y hemorragias en aparato digestivo y otras localizaciones $^{(2,7,8)}$. Un aspecto que suele pasar desapercibido es que el virus del dengue puede afectar a órganos internos, constituyendo las formas viscerales o atípicas como la encefalitis, miocarditis o hepatitis, que pueden tener un curso fatal, y que pueden presentarse en ausencia de extravasación ${ }^{(2)}$. En el presente número de la revista la Dra Godoy L y col. analizaron la frecuencia de bradicardia en casos pediátricos que se hospitalizaron por dengue en un hospital de referencia del Departamento Central del país. Los autores reportan que el $6 \%$ de los pacientes presentaron bradicardia, la gran mayoría benigna que se resolvió en las siguientes dos semanas. Sin embargo en algunos casos puede ser más severa y aparecer bloqueo cardiaco completo, como traducción de una lesión más severa del nodo atroventricular como se evidenció en un caso en la serie de los autores, complicación ya reportada en la literatura ${ }^{(9)}$. Aunque otros cuadros infecciosos se asocian a bradicardia, como difteria, enfermedad de Chagas, o endocarditis ${ }^{(10)}$, la presencia de bradicardia en el contexto de un paciente febril y mialgias podría sugerir que se trataría de un caso de dengue. Estudios previos han demostrado que cuando se compraran pacientes con choque séptico bacteriano con cuadro de choque por dengue, estos últimos presentan menor frecuencia cardiaca que los casos bacterianos $^{(11)}$.

En la última década el Paraguay ha registrado alrededor de 500.000 casos de dengue, y alrededor de 500 muertes. Si se tiene en cuenta el sub-registro de la enfermedad así como los casos asintomáticos, puede poner en perspectiva la gravedad del problema. Los cuatro serotipos ya han circulado en el país. Así el serotipo 3 en el 2007, el serotipo 2 principalmente entre el 2012 y 2013, y el serotipo 1 en los últimos 3 años, con casos ocasionales del serotipo 4. En consecuencia existe una población susceptible a los diferentes serotipos, lo que nos ubica en una situación de riesgo para epidemias de gran envergadura.

Aunque los esfuerzos deben estar dirigidos al

${ }^{1}$ Instituto de Medicina Tropical. Asunción, Paraguay.

${ }^{2}$ Universidad Nacional de Asunción. San Lorenzo, Paraguay.

Correspondencia: Antonio Arbo Correo: antonioarbo@hotmail.com

Recibido: 15/08/2018 Aceptado: 29/08/2018

DOI: https://doi.org/10.31698/ped.45022018001 
control del vector, los resultados han sido decepcionantes. La disponibilidad de vacunas contra el dengue, una de ellas con demostrada eficacia en casos que ya han experimentado un

\section{REFERENCIAS}

1. Simmons CP, Farrar JJ, van Vinh Chau N, Wills B. Dengue. N Engl J Med 2012; 366: 1423-32.

2. World Health Organization. Dengue: Guidelines for Diagnosis, Treatment, Prevention and Control. New ed. Geneva. Switzerland: World Health Organization; 2009.

3. Stanaway JD, Shepard DS, Undurraga EA, Halasa YA, Coffeng LEm,Brady OJ, et al. The global burden of dengue: an analysis from the Global Burden of Disease Study 2013. Lancet Infect Dis 2016; 16:712-23.

4. Suaya JA, Shepard DS, Siqueira JB, Martelli CT, Lum LC, Tan LH, et al. Cost of dengue cases in eight countries in the Americas and Asia: a prospective study. Am J Trop Med Hyg.2009, 80:846-855.

5. Kraemer MU, Sinka ME, Duda KA, Mylne AQ, Shearer FM, Barker CM, et al. The global distribution of the arbovirus vectors Aedes aegypti and Ae. albopictus. ELife 2015;4:e08347.

6. Martínez, E. Dengue y dengue hemorrágico. Aspectos clínicos. Salud Pública Mex. 1995; 37:29-44.

7. Singhi S, Kissoon N, Bansal A. Dengue and dengue hemorrhagic fever: management issues in an intensive care unit. J Pediatr (Rio J). 2007; 83(2 Suppl):S22-35.

8. Lovera D, Martinez de Cuellar C, Araya S, Amarilla S, episodio previo ${ }^{(12)}$, y otra en avanzada fase de desarrollo ${ }^{(13)}$ pueden constituir finalmente las herramientas que permitan el control de esta enfermedad.
Gonzalez N, Aguiar C, et al. Clinical Characteristics and Risk Factors of Dengue Shock Syndrome in Children. Pediatr Infect Dis 2016; 35:1294-99.

9. Navinan MR, Yudhishdran J, Herath S, Liyanage I, Kugadas T, Kumara D, et al. Complete heart block in dengue complicating management of shock due to both bleeding and leakage: a case report. BMC Research Notes 2015; 8:68.

10. Julia Vogler J, Breithardt G, Eckardt L. Bradiarritmias y bloqueos de la conducción. Rev Esp Cardiol. 2012; 65:656-67.

11. Ranjit S, Kissoon N, Gandhi D, Dayal A, Rajeshwari N, Kamath S. Early differentiation between dengue and septic shock by comparison of admission hemodynamic, clinical, and laboratory variables: a pilot study. Pediatric Emergency Care 2007; 23:368-5.

12. Sridhar S, Luedtke A, Langevin E, Zhu M, Bonaparte M, Machabert T, et al. Effect of Dengue Serostatus on Dengue Vaccine Safety and Efficacy. N Engl J Med 2018; 379:327-340.

13. Sáez-Llorens $X$, Tricou V, Yu D, Rivera L, Tuboi S, Garbes $\mathrm{P}$, et al. Safety and immunogenicity of one versus two doses of Takeda's tetravalent dengue vaccine in children in Asia and Latin America: interim results from a phase 2, randomised, placebo-controlled study. Lancet Infect Dis. 2017; 17:615-625. 